\title{
Analysis of stress application at the thoracolumbar junction and influence of vertebral body collapse on the spinal cord and cauda equina
}

\author{
NORIHIRO NISHIDA ${ }^{1}$, TSUKASA KANCHIKU ${ }^{1}$, DAIGO NAKANDAKARI ${ }^{2}$, SHOTA TAHARA $^{2}$, JUNJI OHGI $^{2}$, \\ KAZUHIKO ICHIHARA ${ }^{3}$, ITUO SAKURAMOTO ${ }^{4},{\text { XIAN } \text { CHEN }^{2} \text { and TOSHIHIKO TAGUCHI }}^{1}$ \\ ${ }^{1}$ Department of Orthopedic Surgery, Yamaguchi University Graduate School of Medicine, Ube, Yamaguchi 755-8505; \\ ${ }^{2}$ Department of Mechanical Engineering, Yamaguchi University, Ube, Yamaguchi $755-8611$; ${ }^{3}$ Non-Profit Organization \\ Corporation Japan Orthopedic Biomechanics Institute, Hofu, Yamaguchi 747-0814; ${ }^{4}$ Department of Mechanical and \\ Electrical Engineering, National Institute of Technology Tokuyama College, Shunan, Yamaguchi 745-8585, Japan
}

Received April 13, 2016; Accepted February 24, 2017

DOI: $10.3892 /$ etm. 2017.5570

\begin{abstract}
The thoracolumbar junction comprises the spinal cord, nerve roots and the cauda equina, exhibiting unique anatomical features that may give rise to a diverse array of symptoms under conditions of injury, thus complicating the diagnosis of compressive disorders. The present study aimed to examine varying degrees and forms of compression at this level of the spinal cord using a two-dimensional model to calculate the relationship of these variables to injury. The degree of compression was expressed as a percentage of the spinal canal that was occupied. Results were compared with findings from clinical observations to assess the validity of the model. Analysis revealed that higher levels of compression/spinal canal occupation are associated with the presence of neurological symptoms. This finding was consistent with clinical data. Results of the present analysis warrant further research involving evaluation of compression with respect to other parameters, such as blood flow, as well as more anatomically accurate three-dimensional analysis.
\end{abstract}

\section{Introduction}

The thoracolumbar junction is an area of transition between the posterior curvature of the thoracic spine and the anterior curvature of the lumbar spine that is susceptible to compression fracture with non-union. As this area comprises the spinal cord, nerve roots and the cauda equina, and because of the anatomical feature wherein myelomeres in this region do not

Correspondence to: Dr Norihiro Nishida, Department of Orthopedic Surgery, Yamaguchi University Graduate School of Medicine, 1-1-1 Minami-Kogushi, Ube, Yamaguchi 755-8505, Japan E-mail: nishida3@yamaguchiu.ac.jp

Key words: spinal cord injury, cauda equina, thoracolumbar junction, vertebral body collapse, foot drop align at the level of their corresponding vertebral bodies, diverse symptoms may appear when this region is compromised $(1,2)$. Many diseases other than trauma cause injury to the spinal cord, including disc herniation, ligament ossification and spinal cord tumor. The annual incidence of traumatic spinal cord injury is estimated to be $13-53$ per 1 million individuals (3-6). Independent of the cause, diagnosis is difficult. In the case of delayed spinal cord paralysis caused by a pseudoarthrosis, forward decompression spinal column reconstruction, posterior fusion surgery and vertebroplasty are used as treatment (7-9).

The mechanisms underlying compressive disorders of the spinal cord using the finite element method (FEM) have previously been examined (10-13). However, no analysis of stress application at the level of the medullary cone has been reported. The present study was undertaken to create a model of the spinal cord and cauda equina at the T12/L1 level (a level particularly susceptible to injury) in order to analyse stress at this level and more thoroughly examine its pathophysiology.

\section{Materials and methods}

Construction of setting condition of FEM model. Using 4-node elements with reduced integration in ABAQUS software version 6.9-3 (ABAQUS, Inc., Providence, RI, USA), a two-dimensional model including the white matter, gray matter and pia mater of the spinal cord and cauda equina was created from the T12/L1 cross-sectional computed tomography $(\mathrm{CT})$ images of a pig. The dorsal and ventral roots of L1-5 were distributed surrounding the spinal cord at the level of T12/L1 $(1,2)$. To simulate the spinal nerve branches of the cauda equina and the cauda equina itself, a vertical membrane was set surrounding the nerve fibers within the cauda equina. The anteroposterior dimension of the medullary cone was set at $7.7 \mathrm{~mm}$, while the diameter of the nerve fibers of the cauda equina was set at $0.3 \mathrm{~mm}$. There were 20,131 nodal points and 14,339 elements in total (Fig. 1A).

Bone pieces were assumed to be rigid bodies and were placed in front of the FEM model of the medullary cone and 
cauda equina. The spinal canal was plotted using the CT images and the rigid bodies were arranged around it. The anteroposterior dimension of the spinal canal was set at $14.3 \mathrm{~mm}$ based on analysis of the CT images. The spinal canal was immobilized completely. The bone pieces were initially placed at the position of contact with the anterior aspect of the spinal canal (Fig. 1B). The material constants for gray and white matter were derived from a study published by Ichihara et al (14), while that for the cauda equina was established using our own previously published data $(15,16)$.

Immobilization of the cauda equina. The nerve roots of the cauda equina bifurcate from the spinal cord, each leading into an intervertebral foramen. For this reason, a virtual model of the cauda equina identical in shape to the cauda equina at its initial position was created. The initial position was set with reference to CT myelography and previous studies (1-2). The components of the cauda equina were connected with spring elements to restrict dislocation.

The spring constant for each component of the cauda equina was determined using the beam deflection theory (17). Cauda equina fibers from levels L1-5 are present at the T12/L1 level, with the L1 cauda equina branching from the spinal cord at the T10 level and passing through the L1/L2 intervertebral foramen (1-2). The distance between intervertebral foramina was assumed to be constant (expressed as a) in the range between T10 and S1. Here, if the length (L) of the cauda equina at the level of L1 is assumed to be equal to the distance between the T10 and the L1/L2 intervertebral foramen, there exists a relationship defined by $\mathrm{L}=3.5 \mathrm{a}$. If it is assumed that the cauda equina branches at an interval of $0.5 \mathrm{a}$, its $\mathrm{L}$ at the levels L2 to L5 may be calculated. Vertebral body weight was set at $\mathrm{a}=30 \mathrm{~mm}$ using the $\mathrm{CT}$ images for reference. When external force was applied vertically to the major axis of the cauda equina at the T12/L1 level, nerve roots were relatively free in three dimensions. This allows the assumption that it is a simply supported beam, instead of a nerve root, supporting the organization between cauda equine and intervertebral foramen (Fig. 2).

Regarding the contact of the springs with the cauda equina, two spring elements were set for each point to suppress rotation of the cauda equina. Deflection of the simply supported beam was determined according to the following formula: $\delta=\mathrm{WL}_{1}^{2}\left(\mathrm{~L}-\mathrm{L}_{1}\right)^{2} / 3 \mathrm{LEI}(1)$, where external force is represented by ' $W$ ', deflection by ' $\delta$ ' and cross-sectional secondary movement by 'I'. According to Hooke's law (18), the relationship between $\mathrm{W}$ and $\delta$ is defined as follows: $\mathrm{W}=\mathrm{K} \delta(2)$, in which ' $\mathrm{K}$ ' is the spring constant. Therefore, $\mathrm{K}$ may then be defined as: $\mathrm{K}=3 \mathrm{LEI} / \mathrm{L}_{1}^{2}\left(\mathrm{~L}-\mathrm{L}_{1}\right)^{2}(3)$. If the cauda equina is assumed to be cylindrical, its $I$ is expressed as follows: $I=(\pi / 4) r^{4}(4)$, where radius of the cauda equina is represented by ' $r$ '. Table I demonstrates the results of this calculation for each spring constant.

Definition of the degree of spinal cord/nerve root injury. In the present analysis, equivalent stress $\left(\sigma_{e q}\right)$ was divided by injury stress $\left(\sigma_{A}\right)$ to yield the degree of injury $\left(\sigma_{e q} / \sigma_{A}\right)$. Injury develops if the degree of injury exceeds 1 (19). In a study that performed tensile testing with respect to axons, Galbraith et al (20) reported that white matter axotomy caused $\sim 0.28$ deflection (20). Using data from the study by Galbraith et al (20), the present
Table I. Spring constants for L1-5 of the cauda equina.

\begin{tabular}{lc}
\hline Cauda equina & $K, \mathrm{~N} / \mathrm{m}$ \\
\hline L1 & 0.0045 \\
L2 & 0.0028 \\
L3 & 0.0049 \\
L4 & 0.0123 \\
L5 & 0.0465
\end{tabular}

$K$, spring constant; $\mathrm{N}$, newton; $\mathrm{m}$, mass.

investigation set the injury stress at $0.015 \mathrm{MPa}$, equivalent to the stress experienced during a 0.28 deflection of white matter. As gray matter is destroyed by a deflection of $\sim 0.48$ (14), the injury stress was set at $0.043 \mathrm{MPa}$. As injury of the structure is not related to symptoms, the injury stress for pia mater was set at $3 \mathrm{MPa}$. In an experiment involving compression of a pig cauda equina, Pedowitz et al (21) reported that transmission of electrical signals along nerves was discontinued at $200 \mathrm{mmHg}$ of compression (Fig. 3).

Simulation of compression. Compression analysis was conducted after setting the form of the anterior bone pieces as circles of 180, 160, and 140 degrees with radii of $15 \mathrm{~mm}$ (Fig. 4). The degree of compression was expressed as a percentage of spinal canal occupation (the amount of compressed bone within the spinal canal divided by the sagittal diameter of the spinal canal). A study by Mohanty et al (22) reported that the percentage of spinal canal occupation was proportional to the risk of spinal cord injury. Fig. 5 schematically represents the medullary cone and cauda equina during compression. Mohanty et al (22) additionally investigated the percentage of spinal canal occupied in patients with burst fractures between 2000 and 2005, reporting that the mean percentage was 50\% in cases where neurological symptoms were present and $36 \%$ in cases free of neurological symptoms (22). Therefore, in the present study, compression was applied to an extent resulting in 40,50 or $60 \%$ spinal canal occupation.

In addition, the bone pieces assumed to be rigid bodies were subjected to asymmetrical compression (anterolateral compression), and analysis was conducted at inclination angles of $\alpha=0,10,15$ and $20^{\circ}$ (Fig. 6A). As the actual compression level varies depending on the angle of compression during evaluation of the sagittal section (i.e., determination of the percentage of spinal canal occupied), the percentage occupied by bone pieces (area occupied by bone pieces/pre-compression spinal canal area) was used to determine the level of compression (Fig. 6B) (23). In the present analysis, compression was applied at ratio $=40,50,60$ and $70 \%$. Analysis was conducted under the seven previously mentioned compression settings.

\section{Results}

Stress induced by symmetrical compression. Fig. 7 demonstrates the relationship between the degree of each cauda equina injury and changes in the distribution of injury following an increase in symmetrical anterior compression. In cases of symmetrical 

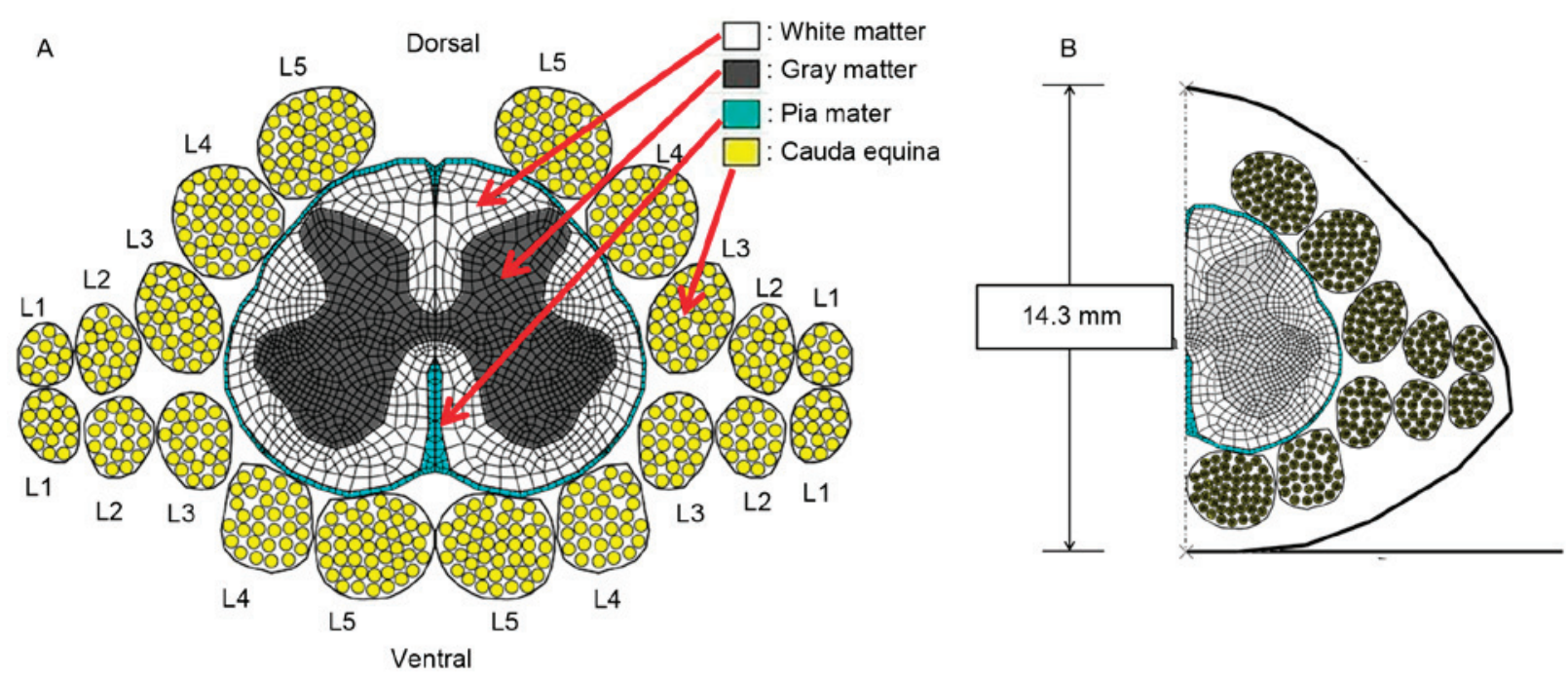

Figure 1. Finite element method model of the medullary cone, cauda equine and spinal canal. (A) The dorsal and ventral roots of L1-5 were distributed around the spinal cord. (B) The anteroposterior dimension of the spinal canal was set at $14.3 \mathrm{~mm}$ based on analysis of computed tomography images.

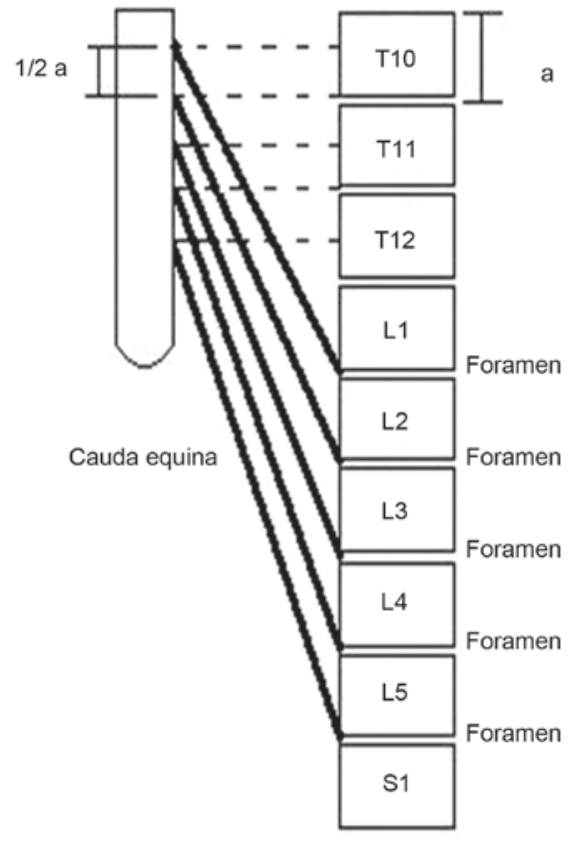

Figure 2. Model of the cauda equina. Pattern diagram of the distance between cauda equine and intervertebral for each foramens. a, the distance between intervertebral foramina assumed to be constant, in the range between T10 and S1. It is assumed that the cauda equina branches at an interval of ' $1 / 2 \mathrm{a}$ '.

anterior compression, the stress within the spinal cord increased with increasing compression. At $40 \%$ compression, stress levels were slightly elevated for each form of compression. When the percentage of spinal canal occupied was $50 \%$, the site within the spinal cord demonstrating elevated levels of stress varied depending on the form of compression, with injury of the spinal cord and cauda equina beginning to appear in the $180^{\circ}$ model. When the percentage of spinal canal occupied was $60 \%$, injury within the spinal canal and cauda equina was observed following each form of compression $\left(160^{\circ}, 140^{\circ}\right.$ and circular). Stress within the spinal cord was highest in the $180^{\circ}$ model (Fig. 7). Fig. 8 demonstrates the percentage of spinal canal occupied following injury of the spinal cord and the L5 ventral root during each form of compression. Injury developed in the spinal cord following compression with $43-51 \%$ spinal canal occupation and in the L5 ventral root following compression with 52-63\% spinal canal occupation.

Stress induced by asymmetrical compression. Fig. 9 demonstrates the relationship between the degree of each cauda equina injury and changes in the distribution of injury following an increase in asymmetrical compression. In cases of asymmetrical compression, levels of elevated stress at the center of the spinal cord's dorsal funiculus differed slightly depending on the inclination angle until 50\% spinal canal occupation was reached. When the occupied percentage was $60 \%$, unilaterally marked stress elevation within the spinal cord was observed at inclination angles of $\alpha=10^{\circ}$ or higher, with stress elevation becoming more evident at $70 \%$ compression. Fig. 10 demonstrates the percentage of spinal canal occupied upon injury of the spinal cord and right L5 ventral root at each form and angle of compression. Injury was induced in the spinal cord following compression with 43-48\% spinal canal occupation and in the L5 ventral root following compression with 58-61\% spinal canal occupation.

\section{Discussion}

The thoracolumbar junction is composed of high- and low-level motor neurons of the spinal cord parenchyma, cauda equina and nerve roots. Due to its unique structure, diverse symptoms may appear in this area, making it difficult to distinguish their exact origin (24-26). Slight differences in lesions may lead to the appearance of diverse neurological symptoms. For example, spastic paralysis, flaccid paralysis or both may arise from slight differences in the affected level of the thoracolumbar junction or the medullary cone $(24,25)$. Foot drop may also occur. Disorders arising at the level of the thoracolumbar junction reflect disorders of the L5 ventral root, while foot drop is also reflective of injury to the L5 nerve root due to disorders such as fibular nerve paralysis, cerebral disease and lumbar spondylosis, making the diagnosis more 

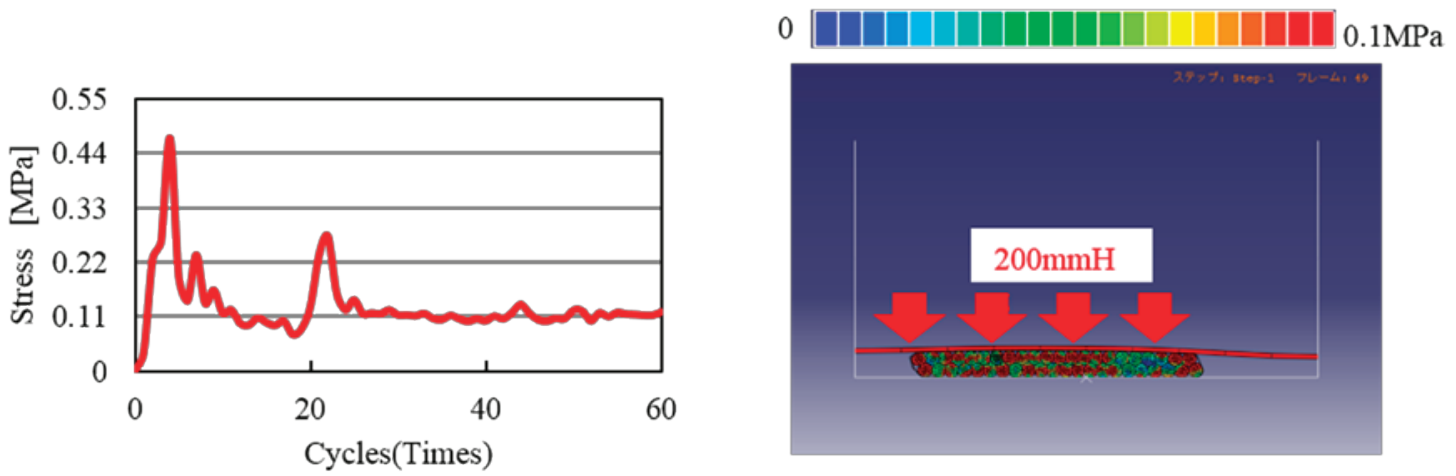

Figure 3. Degree of spinal cord/nerve root injury. The cauda equina was exposed to compression at $200 \mathrm{mmHg}$, which is equal to $0.027 \mathrm{MPa}$. An injury stress of $0.11 \mathrm{MPa}$ was therefore adopted for the cauda equina.
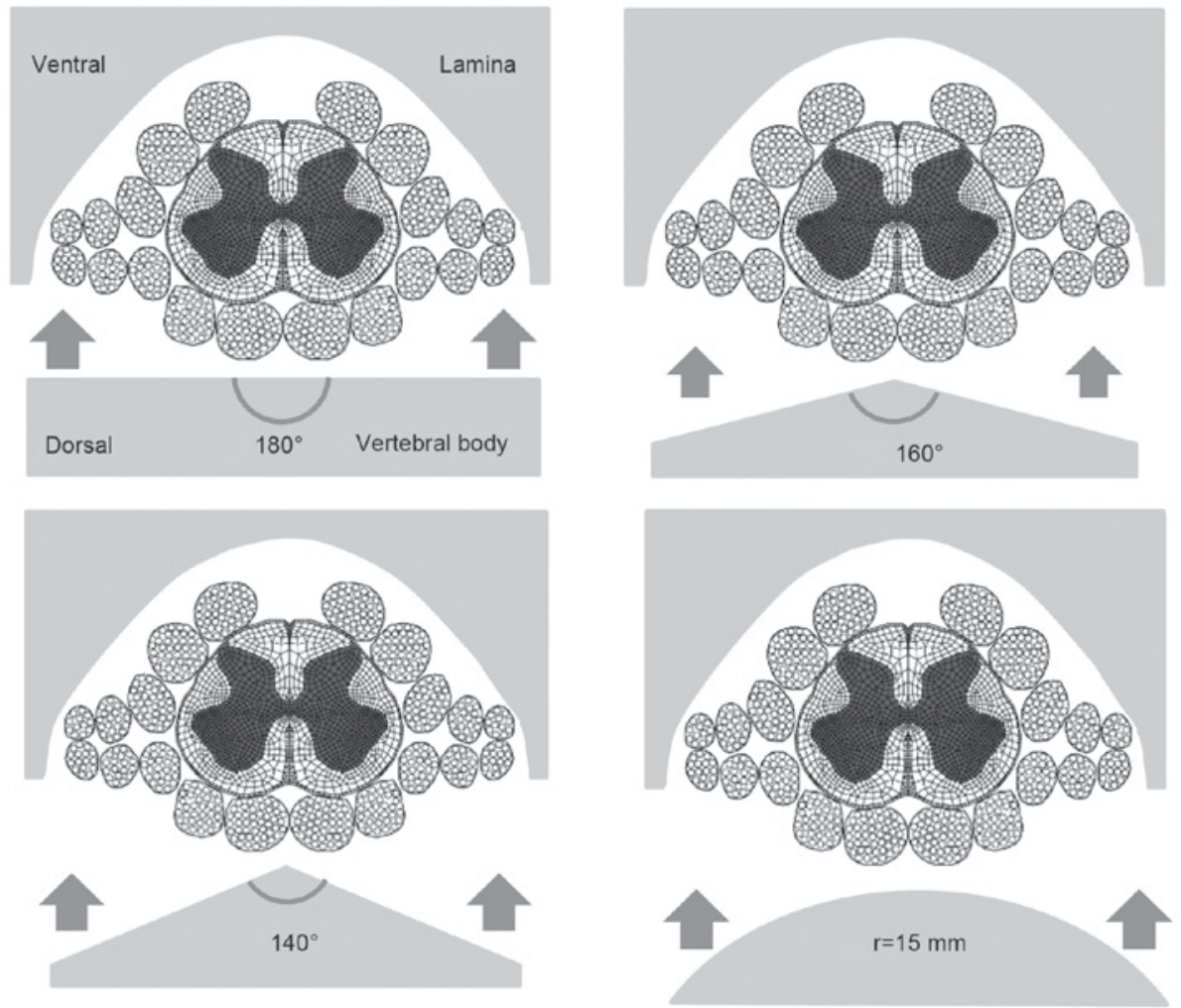

Figure 4. Compression analysis. Compression analysis was conducted after setting the form of the anterior bone pieces as circles of 180,160 , and $140^{\circ}$ with radii of $15 \mathrm{~mm}$.
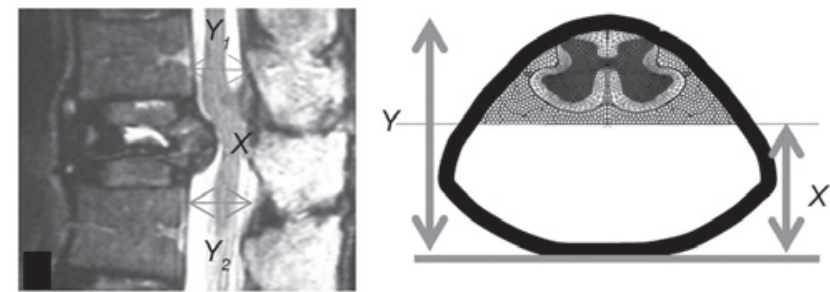

The percentage of spinal canal occupied $=X \div\left(Y_{1}+Y_{2}\right) / 2$

Figure 5. Degree of compression. The degree of compression was expressed as the percentage of spinal canal occupied (the amount of compressed bone within the spinal canal divided by the sagittal diameter of the spinal canal). $\mathrm{X}$, Anteroposterior diameter of bone fragment; Y, Cranial and caudal spinal canal distance of injury level. difficult (27-34). Diseases of the thoracolumbar junction include degenerative diseases, such as disc herniation and ossification of yellow ligaments. In recent years, delayed paralysis following osteoporotic vertebral fracture has been increasing among the elderly population (35-37). Considering this vast array of circumstances, the present study was undertaken to evaluate the influence of the degree and form of compression on the spinal cord and cauda equina.

Regarding the relationship between spinal canal stenosis and neurological symptoms, a study by Denis (38) reported that neurological symptoms were observed in cases where the percentage of spinal canal occupation was $\geq 75 \%$ and were rarely seen when the percentage was $25-50 \%$ or lower. A study by Hashimoto et al (39) reported the presence of the risk of 


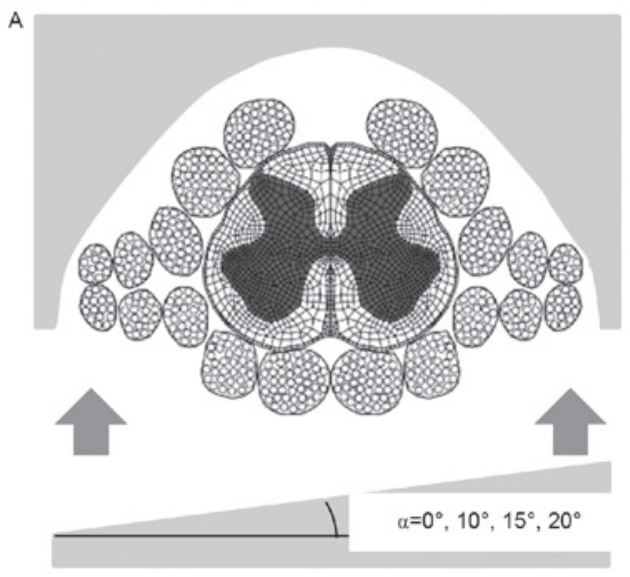

B

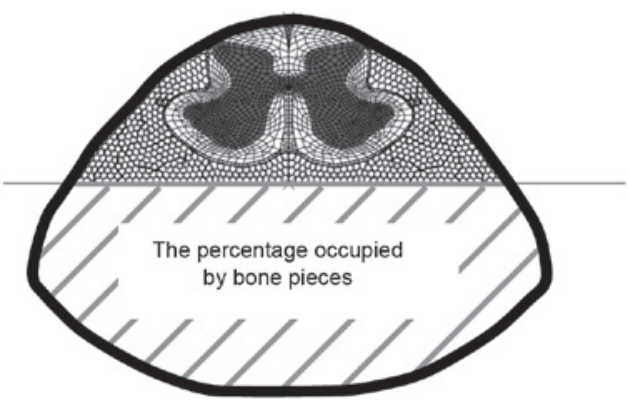

Figure 6. Anterolateral compression model. (A) The bone pieces assumed to be rigid bodies were subjected to asymmetrical compression (anterolateral compression), and analysis was conducted at inclination angles of $\alpha=0,10,15$ and $20^{\circ}$. (B) The percentage of the spinal canal occupied by bone pieces (area occupied by bone pieces/pre-compression spinal canal area).
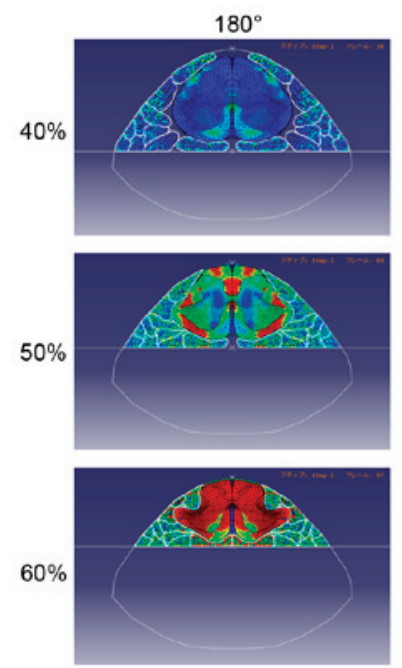
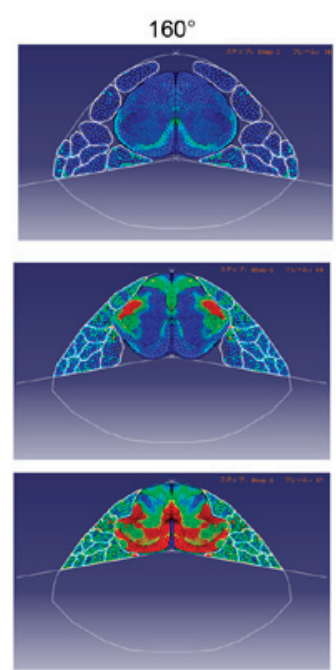

0
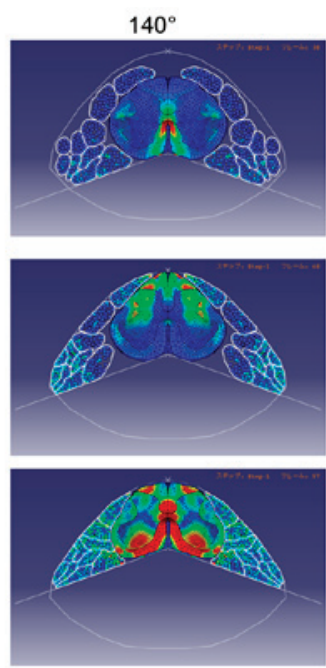

1

Scale of degree of injury
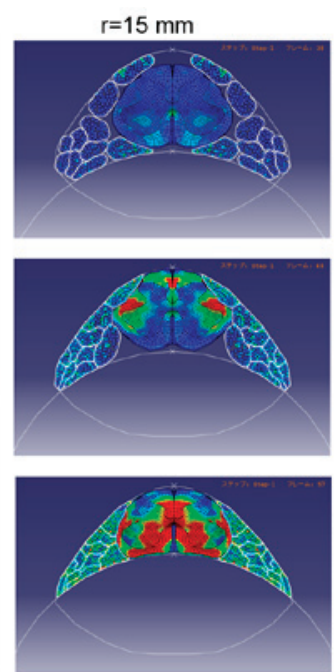

Figure 7. Symmetrical anterior compression model. The landscape color bar represents the degree of injury with red indicating the damaged section. Compression analysis was conducted after setting the form of the anterior bone pieces as circles of 180,160 and $140^{\circ}$ with radii of 15 mm. Compression was applied to an extent resulting in 40,50 or $60 \%$ spinal canal occupation.

neuropathy when the percentage of spinal canal occupation was $\geq 35 \%$ at the T11/12 level, $\geq 45 \%$ at $\mathrm{L} 1$ and $\geq 55 \%$ at levels L2 and lower. A study by Kim et al (40) also reported similar results. These previous reports indicate that the risk of paralysis increases as the percentage of spinal canal occupation increases, even when the degree of compression is small.

Multiple reports have been made from the standpoint of conventional spinal cord biomechanics. Studies by Kato et al (41-43) conducted analyses using a model of spinal cord hemisection that involved application of external force to a particular layer of the spinal cord. Studies by Li et al $(44,45)$ investigated spinal cord mobility using a full-circumferential model of the spinal cord, without setting levels of compression in the surrounding area. A study by Takahashi et al (46) created a two-dimensional model of preoperative and postoperative compression, expressed as a sagittal section, without evaluating axial images of the spinal cord. Studies by
Czyz et al $(47,48)$ created a three-dimensional model of the spinal cord. Studies by Maikos et al (49) and Greaves et al (50) created models of the spine and spinal cord for analysis of spinal cord kinetics and spinal cord stress due to compression. Our previous research has also involved analyses of spinal cord stress and the results demonstrated consistency with the aforementioned clinical findings; however, such previous analyses did not include the kinetics of the spinal cord and nerve roots (8-10).

Regarding the degree of cauda equina injury, the present study revealed that each type of compression is able to induce injury to the L5 ventral root. This is because the L5 ventral root is located in front of the spinal cord and may become pinched between the spinal cord and surrounding bone pieces. This suggests that it may be possible for foot drop to develop if the anterior bone pieces touch the L5 ventral root due to instability of the vertebral body. Analysis of the results of 

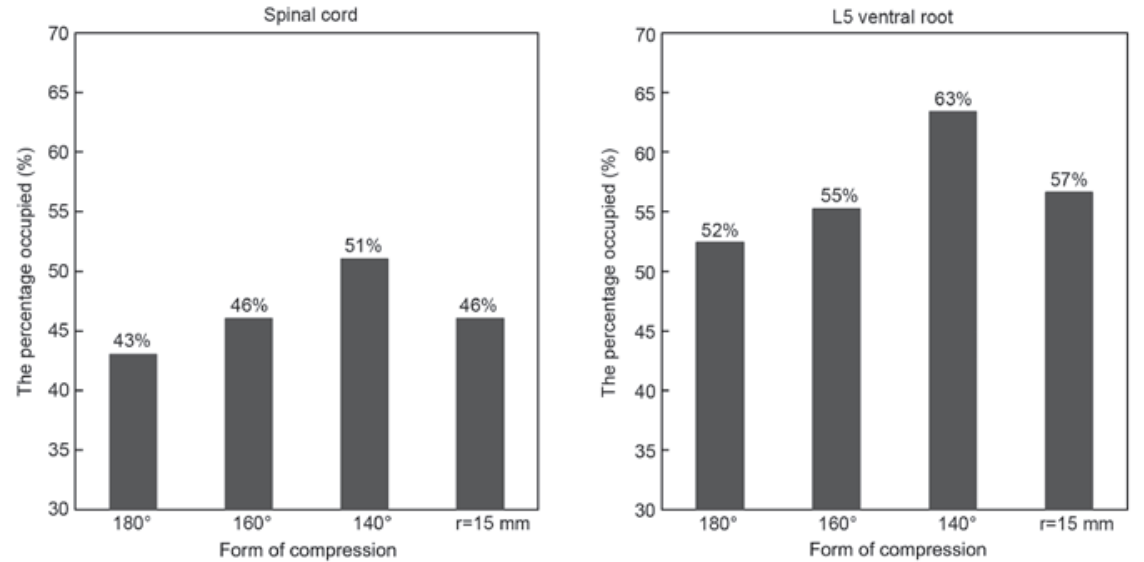

Figure 8. Percentage of spinal canal occupied following injury of the spinal cord and the L5 ventral root during each form of compression radius. Compression amount exceeding the degree of injury $\left(\sigma_{e q} / \sigma_{A}\right) 1$.
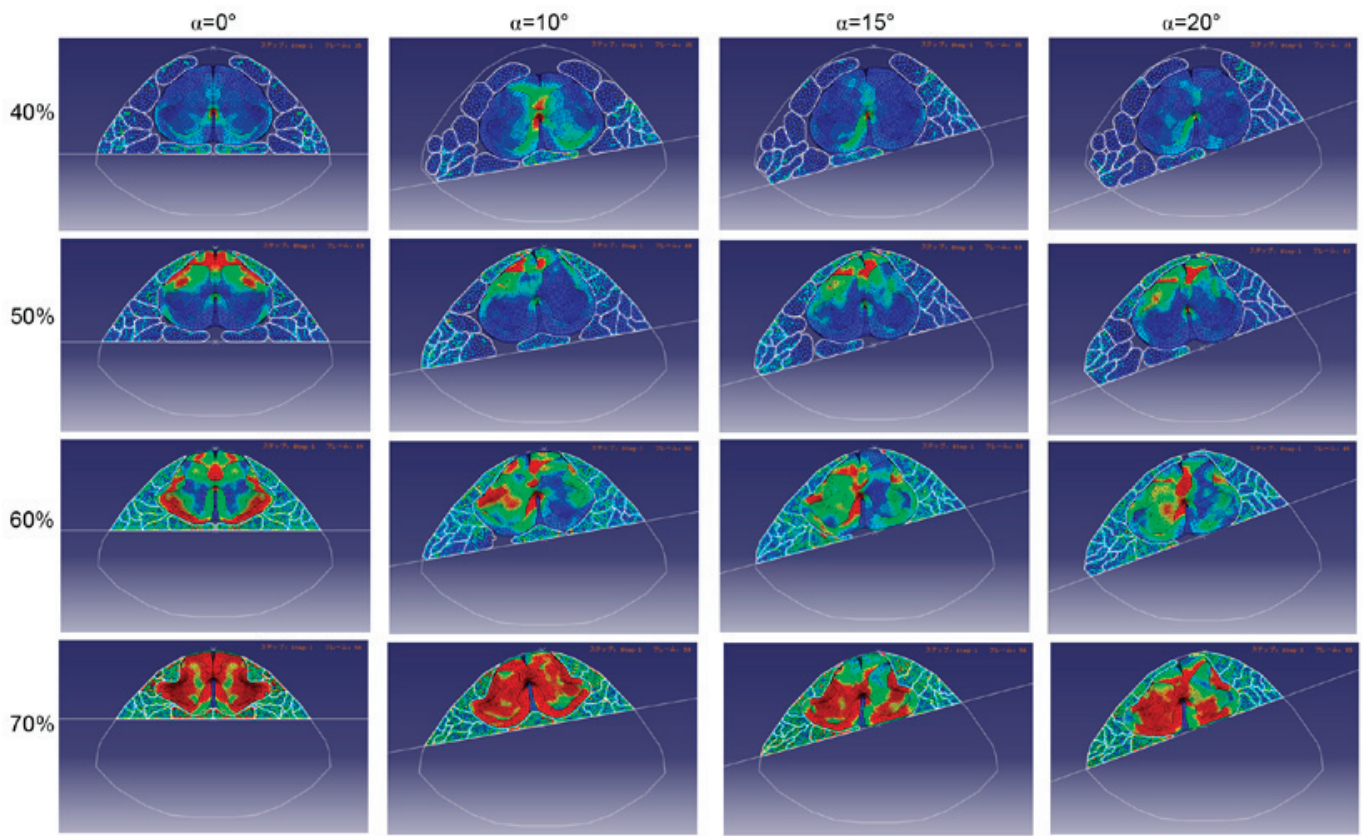

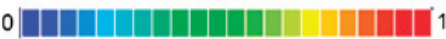

Scale of degree of injury

Figure 9. Asymmetrical anterior compression model. The landscape color bar represents the degree of injury, with red indicating the damaged section. Analysis was conducted at inclination angles of $\alpha=0,10,15$ and $20^{\circ}$. Compression was applied at ratio $=40,50,60$ and $70 \%$.
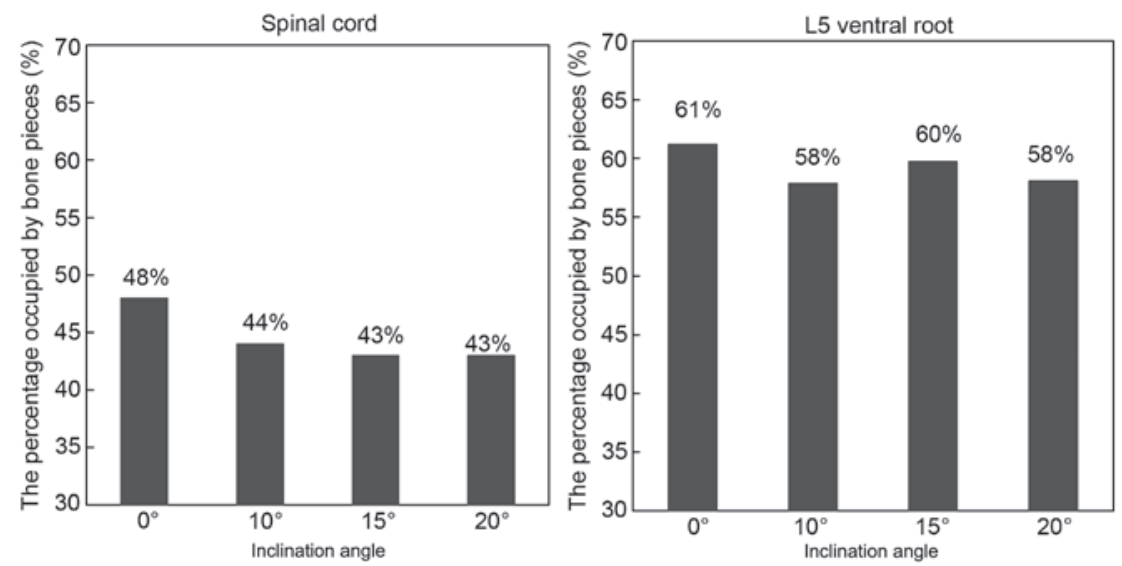

Figure 10. Percentage of spinal canal occupied upon injury of the spinal cord and right L5 ventral root at each form and angle of compression. Compression amount exceeding the degree of injury $\left(\sigma_{e q} / \sigma_{A}\right) 1$. 
the present study supports this possibility. In the present study, when injury occurred, the percentage of spinal canal occupation was $43-51 \%$ at the spinal cord and $52-63 \%$ at the cauda equina (L5 ventral root), while the percentage occupied by bone pieces was $43-48 \%$ at the spinal cord and $58-61 \%$ at the cauda equina (L5 ventral root). This finding is consistent with the aforementioned clinical data. Although this was a two-dimensional evaluation, the findings of the present study may be considered relevant and may be important in clinical practice. Additional analysis revealed that compression of $\geq 48 \%$ in any form may induce myelopathy and that compression of $\geq 52 \%$ may result in the development of foot drop, as previously demonstrated (38-40).

The present study had several limitations. The study did not account for blood flow, dentate ligaments or cerebrospinal fluid. The study also used a two-dimensional model, which is unable to assess the possibility of avoiding injury at higher levels of compression due to three-dimensional motion of the cauda equina. The motion of the cauda equina was defined on the basis of a spring, thus making it impossible to consider the possibility of free motion. Despite these limitations, the observed differences in the manner of injury between the spinal cord and cauda equina depending on the angle and level of compression are consistent with previous clinical findings and may encourage further advances in research in this field, including three-dimensional analysis.

Analysis of compression of the spinal cord and cauda equina at the thoracolumbar junction in the present study revealed differences at the injured sites depending on the angle and level of compression. It was also observed that the risk for appearance of symptoms increases with levels of compression of $\geq 50 \%$, which is consistent with previous clinical findings. In conclusion, the results of the present study suggest that nerve injury at the thoracolumbar junction may vary depending on the form and other features of compression, and that this feature complicates diagnosis of disorders at this level of the spinal cord.

\section{Acknowledgements}

The authors would like to thank the staff and the graduate students of the Department of Mechanical Engineering, Yamaguchi University (Yamaguchi, Japan) for their cooperation, and the Department of Mechanical and Electrical Engineering, National Institute of Technology Tokuyama College (Yamaguchi, Japan).

\section{References}

1. Wall EJ, Cohen MS, Massie JB, Rydevik B and Garfin SR: Cauda equina anatomy. I: Intrathecal nerve root organization. Spine (Phila Pa 1976) 15: 1244-1247, 1990.

2. Wall EJ, Cohen MS, Abitbol JJ and Garfin SR: Organization of intrathecal nerve roots at the level of the conus medullaris. J Bone Joint Surg Am 72: 1495-1499, 1990.

3. Lee BB, Cripps RA, Fitzharris M and Wing PC: The global map for traumatic spinal cord injury epidemiology: Update 2011, global incidence rate. Spinal Cord 52: 110-116, 2014.

4. Noonan VK, Fingas M, Farry A, Baxter D, Singh A, Fehlings MG and Dvorak MF: Incidence and prevalence of spinal cord injury in Canada: A national perspective. Neuroepidemiology 38: 219-226, 2012.

5. van Asbeck FW, Post MW and Pangalila RF: An epidemiological description of spinal cord injuries in The Netherlands in 1994. Spinal Cord 38: 420-424, 2000.
6. Wyndaele M and Wyndaele JJ: Incidence, prevalence and epidemiology of spinal cord injury: What learns a worldwide literature survey? Spinal Cord 44: 523-529, 2006.

7. Uchida K, Kobayashi S, Nakajima H, Kokubo Y, Yayama T, Sato R, Timbihurira $\mathrm{G}$ and Baba H: Anterior expandable strut cage replacement for osteoporotic thoracolumbar vertebral collapse. J Neurosurg Spine 4: 454-462, 2006.

8. Uchida K, Kobayashi S, Matsuzaki M, Nakajima H, Shimada S, Yayama T, Sato R and Baba H: Anterior versus posterior surgery for osteoporotic vertebral collapse with neurological deficit in the thoracolumbar spine. Eur Spine J 15: 1759-1767, 2006.

9. Uchida K, Nakajima H, Yayama T, Miyazaki T, Hirai T, Kobayashi S, Chen K, Guerrero AR and Baba $\mathrm{H}$ : Vertebroplasty-augmented short-segment posterior fixation of osteoporotic vertebral collapse with neurological deficit in the thoracolumbar spine: Comparisons with posterior surgery without vertebroplasty and anterior surgery. J Neurosurg Spine 13: 612-621, 2010.

10. Nishida N, Kanchiku T, Kato Y, Imajo Y, Kawano S and Taguchi T: Biomechanical analysis of the spinal cord in Brown-Séquard syndrome. Exp Ther Med 6: 1184-1188, 2013.

11. Nishida N, Kanchiku T, Kato Y, Imajo Y, Yoshida Y, Kawano S and Taguchi T: Biomechanical analysis of cervical myelopathy due to ossification of the posterior longitudinal ligament: Effects of posterior decompression and kyphosis following decompression. Exp Ther Med 7: 1095-1099, 2014.

12. Nishida N, Kato Y, Imajo Y, Kawano S and Taguchi T: Biomechanical study of the spinal cord in thoracic ossification of the posterior longitudinal ligament. J Spinal Cord Med 34: 518-522, 2011.

13. Nishida N, Kato $\mathrm{Y}$, Imajo $\mathrm{Y}$, Kawano $\mathrm{S}$ and Taguchi $\mathrm{T}$ : Biomechanical analysis of cervical spondylotic myelopathy: The influence of dynamic factors and morphometry of the spinal cord. J Spinal Cord Med 35: 256-261, 2012.

14. Ichihara K, Taguchi T, Shimada Y, Sakuramoto I, Kawano S and Kawai S: Gray matter of the bovine cervical spinal cord is mechanically more rigid and fragile than the white matter. J Neurotrauma 18: 361-367, 2001.

15. Ichihara K, Taguchi T, Sakuramoto I, Kawano S and Kawai S: Mechanism of the spinal cord injury and the cervical spondylotic myelopathy: New approach based on the mechanical features of the spinal cord white and gray matter. J Neurosurg 99 (3 suppl): S278-S285, 2003.

16. Tunturi AR: Elasticity of the spinal cord, pia, and denticulate ligament in the dog. J Neurosurg 48: 975-979, 1978.

17. Cowper GR: The shear coefficient in Timeshenko's beam theory. J Appl Mech 33: 335-340, 1966.

18. Hooke R: Lectures de potentia restitutiva, or of spring explaining the power of springing bodies. London Martyn 6: 1-564, 1678.

19. Miner MA: Cumulative damage in fatigue. Journal of Applied Mechanics 12: 159-164, 1945.

20. Galbraith JA, Thibault LE and Matteson DR: Mechanical and electrical responses of the squid giant axon to simple elongation. J Biomech Eng 115: 13-22, 1993.

21. Pedowitz RA, Garfin SR, Massie JB, Hargens AR, Swenson MR, Myers RR and Rydevik BL: Effects of magnitude and duration of compression on spinal nerve root conduction. Spine (Phila Pa 1976) 17: 194-199, 1992

22. Mohanty SP, Bhat NS, Abraham R and Ishwara Keerthi C: Neurological deficit and canal compromise in thoracolumbar and lumbar burst fractures. J Orthop Surg (Hong Kong) 16: 20-23, 2008.

23. Nojiri H, Inoue Y, Kaneko K, Uta J and Yobe M: Appearance of neurologic deficits in patients with thoracolumbar burst fractures. Journal of Japanese Society for Fracture Repair 23: 59-62, 2001.

24. Elsberg C: Diagnosis and treatment of surgical disease of the spinal cord and its membranes. WB Saunders: 63-65, 1969.

25. Hollinshead WH: Anatomy for Surgeons. Hoeber Medical Division. Harper and Row. New York, San Francisco, London, pp182, 1969.

26. Tokuhashi Y, Matsuzaki H, Uematsu Y and Oda H: Symptoms of thoracolumbar junction disc herniation. Spine 26: E512-E518, 2001.

27. Cambell WW: DeJong's the Neurologic Examination. 7th edition. Philadelphia, Wolters Kluwer, pp663-687, 2013.

28. Aono H, Iwasaki M, Ohwada T, Okuda S, Hosono N, Fuji T and Yoshikawa H: Surgical outcome of drop foot caused by degenerative lumbar diseases. Spine 32: E262-E266, 2007.

29. Aono H, Nagamoto Y, Tobimatsu H, Takenaka S and Iwasaki M: Surgical outcomes for painless drop foot due to degenerative lumbar disorders. J Spinal Disord Tech 27: E258-E261, 2014. 
30. Baysefer A, Erdoğan E, Sali A, Sirin S and Seber N: Foot drop following brain tumors: Case reports. Minim Invasive Neurosurg 41: 97-98, 1998.

31. Eskandary H, Hamzei A and Yasamy MT: Foot drop following brain lesion. Surg Neurol 43: 89-90, 1995.

32. Hanakita J, Suwa H, Ohta F, Nishi S, Sakaida H and Iihara K: Neuroradiological examination of thoracic radiculomyelopathy due to ossification of the ligamentum flavum. Neuroradiology 32 38-42, 1990.

33. Naylor A: Late results of laminectomy for lumbar disc prolapse. A review after ten to twenty-five years. J Bone Joint Surg Br 56: 17-29, 1974.

34. Shiokawa K, Hanakita J, Suwa H, Saiki M, Oda M and Kajiwara M: Clinical analysis and prognostic study of ossified ligamentum flavum of the thoracic spine. J Neurosurg 94 (2 Suppl): S221-S226, 2001.

35. Hasegawa K, Homma T, Uchiyama S and Takahashi H: Vertebral pseudarthrosis in the osteoporotic spine. Spine (Phila $\mathrm{Pa}$ 1976) 23: 2201-2206, 1998.

36. Kaneda K, Asano S, Hashimoto T, Satoh S and Fujiya M: The treatment of osteoporotic-posttraumatic vertebral collapse using the Kaneda device and a bioactive ceramic vertebral prosthesis. Spine (Phila Pa 1976) 17 (8 Suppl): S295-S303, 1992.

37. Kumpan W, Salomonowitz E, Seidl G and Wittich GR: The intravertebral vacuum phenomenon. Skeletal Radiol 15: 444-447, 1986.

38. Denis F: The three column spine and its significance in the classification of acute thoracolumbar spinal injuries. Spine 8: 817-831, 1983.

39. Hashimoto T, Kaneda K and Abumi K: Relationship between traumatic spinal canal stenosis and neurologic deficits in thoracolumbar burst fractures. Spine (Phila Pa 1976) 13: 1268-1272, 1988.

40. Kim NH, Lee HM and Chun IM: Neurologic injury and recovery in patients with burst fracture of the thoracolumbar spine. Spine (Phila Pa 1976) 24: 290-294, 1999.

41. Kato Y, Kanchiku T, Imajo Y, Kimura K, Ichihara K, Kawano S, Hamanaka D, Yaji D and Taguchi T: Biomechanical study of the effect of degree of static compression of the spinal cord in ossification of the posterior longitudinal ligament. J Neurosurg Spine 12: 301-305, 2009.
42. Kato $\mathrm{Y}$, Kanchiku T, Imajo Y, Ichinara K, Kawano S, Hamanama D, Yaji D and Taguchi T: Flexion model simulating spinal cord injury without radiographic abnormality in patients with ossification of the longitudinal ligament: The influence of flexion speed on the cervical spine. J Spinal Cord Med 32: $555-559,2009$

43. Kato Y, Kataoka H, Ichihara K, Imajo Y, Kojima T, Kawano S, Yaji D and Taguchi T: Biomechanical study of cervical flexion myelopathy using a three-dimensional finite element method. J Neurosurg Spine 8: 436-441, 2008.

44. Li XF and Dai LY: Three-dimensional finite element model of the cervical spinal cord: Preliminary results of injury mechanism analysis. Spine (Phila Pa 1976) 34: 1140-1147, 2009.

45. Li XF and Dai LY: Acute central cord syndrome: Injury mechanisms and stress features. Spine (Phila Pa 1976) 35: E955-E964, 2010.

46. Takahashi K, Ozawa H, Sakamoto N, Minegishi Y, Sato M and Itoi E: Influence of intramedullary stress on cervical spondylotic myelopathy. Spinal Cord 51: 761-764, 2013.

47. Czyż M, Scigała K, Jarmundowicz W and Będziński R: Numerical model of the human cervical spinal cord-the development and validation. Acta Bioeng Biomech 13: 51-58, 2011.

48. Czyż M, Ścigała K, Będziński R and Jarmundowicz W: Finite element modelling of the cervical spinal cord injury-clinical assessment. Acta Bioeng Biomech 14: 23-29, 2012.

49. Maikos JT, Qian Z, Metaxas D and Shreiber DI: Finite element analysis of spinal cord injury in the rat. J Neurotrauma 25: 795-816, 2008

50. Greaves CY, Gadala MS and Oxland TR: A three-dimensional finite element model of the cervical spine with spinal cord: An investigation of three injury mechanisms. Ann Biomed Eng 36: 396-405, 2008.

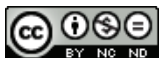

This work is licensed under a Creative Commons Attribution-NonCommercial-NoDerivatives 4.0 International (CC BY-NC-ND 4.0) License. 